\title{
Educação empreendedora na educação básica e o homem parentético de Guerreiro Ramos
}

\section{Entrepreneurial education in basic education and the parenthetic man of Guerreiro Ramos}

Recebido em 06.07.2017. Aprovado em 30.08.2017 Avaliado pelo sistema double blind review

Bruno Francisco Batista Dias

brunofbd@id.uff.br

Universidade Federal Fluminense - Volta Redonda - RJ

Sandra Regina Holanda Mariano

sandramariano@id.uff.br

Universidade Federal Fluminenses - Niterói - RJ

\section{Resumo}

A questão que orientou este artigo foi: o quanto as escolas de educação básica estão contribuindo para 0 desenvolvimento do homem parentético de Guerreiro Ramos? Parentético porque é o tipo de homem que consegue colocar entre 'parênteses', em 'suspenso' "a crença no mundo comum, permitindo ao indivíduo alcançar um nível de pensamento conceitual e, portanto, de liberdade" (GUERREIRO RAMOS, 1984, p. 8). O homem parentético busca, deliberadamente, o olhar diferenciado, a perspectiva de um estranho em seu próprio meio social, de maneira a maximizar sua compreensão da organização e da sua vida para poder agir e interferir para transformar o que está posto, o que está convencionalmente estabelecido. A pesquisa foi realizada nos periódicos nacionais da área de Administração disponíveis nas bases SciELO e SPELL. A partir dos artigos publicados encontrados, verificou-se que é possível afirmar que há no Brasil um movimento para desenvolver programas de educação empreendedora na educação básica que buscam elevar a autoestima e o nível de controle dos estudantes sob seu próprio destino, propiciando-lhes maior autonomia, autorrealização e crescimento pessoal, características essenciais para o homem parentético de Guerreiro Ramos. Por fim, é preciso lembrar que o próprio Guerreiro Ramos (1984) afirmava que, se era possível educar os sujeitos para o desenvolvimento do homem operacional, que se preocupa, fundamentalmente, com a manutenção do sistema social e, do homem reativo, cujo objetivo é, basicamente, o ajustamento ao contexto do trabalho e não seu crescimento pessoal; também seria possível educar para desenvolver 0 homem parentético.

Palavras-chaves: Educação Empreendedora. Ensino de Empreendedorismo. Educação Básica. Educação Pública. Homem Parentético.

\section{Abstract}

The question that drives this article is: how much are basic education schools contributing to the development of the "parenthetic man" of Guerreiro Ramos? A "parenthetic" means he is the type of man who can put between 'parentheses', 'suspended' "the belief in the common world, allowing the individual to reach a level of conceptual thought and, therefore, of freedom "(GUERREIRO RAMOS, 1984, p. 8). The "parenthetic man" looks in a diferente perspective like a stranger in his own social environment, to maximize his understanding of the organization and his own life to act, to interfere and to transform the reality, which is conventionally established. The research used the data from national journals of the Administration area available in the SciELO and SPELL databases. From the articles found, it is possible to affirm that there is in Brazil a movement to develop programs of entrepreneurial education in basic education that pretends to raise the 
self-esteem and the level of control of the students under their own destiny, giving them greater Autonomy, self-realization and personal growth, essential characteristics for the man of Guerreiro Ramos. Finally, it should be remembered that Guerreiro Ramos himself (1984) affirmed that if it was possible to educate the subjects for the development of the operational man, who is fundamentally concerned with the maintenance of the social system and of the reactive man whose objective It is basically the adjustment to the context of the work and not its personal growth; It would also be possible to educate to develop the "parenthetic man".

Keywords: Entrepreneurial Education. Teaching of Entrepreneurship. Basic education. Public education. Parenthetic Man.

\section{Introdução}

Já em 1984, Guerreiro Ramos assinalava a importância do reconhecimento e estímulo à existência do 'Homem Parentético', homem que não iria esforçar-se demasiadamente apenas para obter sucesso, segundo os padrões convencionais, como faz aquele cujo objetivo é só alcançar altos cargos na organização. O homem parentético, de acordo com Guerreiro Ramos (1984, p. 9), daria grande importância ao eu, e teria urgência em encontrar um significado para a vida. Não aceitaria acriticamente padrões de desempenho, embora pudesse ser um grande empreendedor quando Ihe atribuíssem tarefas criativas. Não trabalharia apenas para fugir à apatia ou indiferença, porque o comportamento passivo iria ferir seu senso de autoestima e autonomia. Iria esforçar-se para influenciar o ambiente, para retirar dele tanta satisfação quanto pudesse. Seria ambivalente em relação à organização.

Ambivalente porque sua compreensão, por um lado, aponta que as organizações, como são limitadas pela racionalidade funcional, têm de ser tratadas segundo seus próprios termos relativos, mas, por outro lado, há a percepção de que, nestas mesmas organizações, também é possível obter satisfação e autonomia, empreender, criar e se emancipar.

De fato, "a história contemporânea está gestando um novo tipo de homem ao qual denominei 'o homem parentético'" (GUERREIRO RAMOS, 1984, p. 4). Parentético porque é o tipo de homem que consegue colocar entre 'parênteses', em 'suspenso' "a crença no mundo comum, permitindo ao indivíduo alcançar um nível de pensamento conceitual e, portanto, de liberdade" (GUERREIRO RAMOS, 1984, p. 8). O homem parentético busca, deliberadamente, o olhar diferenciado, a perspectiva de um estranho em seu próprio meio social, de maneira a maximizar sua compreensão da organização e da vida para poder agir e interferir para transformar o que está posto, o que está convencionalmente estabelecido.

Na realidade, de acordo com Guerreiro Ramos (1984, p. 7), "o homem parentético não pode deixar de ser um participante da organização. Porém, justamente por tentar ser autônomo, ele não pode ser psicologicamente enquadrado como aqueles indivíduos que se comportam de acordo com os modelos reativo e operacional". Segundo o próprio Guerreiro Ramos (1984, p. 8), o homem parentético, também, é "simultaneamente, um reflexo das novas circunstâncias sociais, que agora são mais perceptíveis nas sociedades industriais avançadas, como a dos EUA, que irão prevalecer eventualmente pelo mundo inteiro, e uma reação a elas".

Assim, do mesmo modo que os indivíduos foram educados para o desenvolvimento do homem operacional, que se preocupa, fundamentalmente, com a manutenção do sistema social e, do homem reativo, cujo objetivo é, basicamente, o ajustamento ao contexto do trabalho e não seu crescimento pessoal (GUERREIRO RAMOS, 1984, p. 5), faz-se necessário educar para que os indivíduos desenvolvam as características do homem parentético, ou seja, para que desenvolvam a capacidade de colocar as circunstâncias ou sua realidade entre parênteses, analisa-las e, a partir, daí propor mudanças e transformar a realidade, ainda que comece por transformar, apenas, a sua própria realidade, seu contexto social.

Destaca-se que este indivíduo se assemelha ao sujeito cujas características buscam ser desenvolvidas nos programas de educação empreendedora. Isto posto que, o empreendedor, assim como o homem 
parentético, não se limita às condições postas, à realidade estabelecida, portanto, às condições convencionalmente estabelecidas da sociedade a que pertence. Ao contrário, o empreendedor, como homem parentético, busca autorrealização, autonomia e emancipação. Deste modo, a formação para 0 empreendedorismo ou para a atitude empreendedora seria fundamental, tanto para o desenvolvimento das organizações, quanto para dos indivíduos que as compõem. Lembrando que, como destacou Guerreiro Ramos (1984, p. 7), "o homem parentético não pode deixar de ser um participante da organização".

Nesse sentido, a questão seminal que orientou este artigo foi: o quanto as escolas de educação básica estão contribuindo para o desenvolvimento deste novo individuo com características do homem parentético? Buscou-se evidenciar esta resposta através de uma pesquisa nos periódicos nacionais da área de Administração disponíveis nas bases Scientific Electronic Library Online (SciELO) e Scientific Periodicals Electronic Library (SPELL).

\section{O homem parentético de Guerreiro Ramos e as possibilidades através da educação empreendedora (ensino do empreendedorismo) na educação básica}

A priori, faz-se necessário esclarecer que a Lei no 9.394, de 20 de dezembro de 1996, conhecida como Lei de Diretrizes e Bases da Educação (LDB), definiu que "A educação abrange os processos formativos que se desenvolvem na vida familiar, na convivência humana, no trabalho, nas instituições de ensino e pesquisa, nos movimentos sociais e organizações da sociedade civil e nas manifestações culturais". Quanto à organização do ensino, o artigo $4^{\circ}$ assinala que a educação básica obrigatória e gratuita é definida dos 4 (quatro) aos 17 (dezessete) anos de idade e organizada em três etapas, a saber: pré-escola, ensino fundamental ( $1^{\circ}$ ao $9^{\circ}$ ano), ensino médio $\left(10^{\circ}\right.$ ao $12^{\circ}$ ano).

Nos termos da Lei $n^{\circ} 9.394$, de 20 de dezembro de 1996, o objeto de estudo da pesquisa em pauta, portanto, são aqueles trabalhos publicados que, de algum modo, abordam a temática da educação empreendedora (ensino do empreendedorismo) em organizações que oferecem pré-escola e/ou ensino fundamental e/ou ensino médio. A partir da análise destes trabalhos verificamos o quanto as escolas de educação básica estão contribuindo para o desenvolvimento do homem parentético.

Neste caso, de volta a Guerreiro Ramos, Azevedo e Albernaz (2006, p. 7) afirmam que, "de modo geral, podemos afirmar que os textos (de Guerreiro Ramos) guardam uma preocupação de fundo: até que ponto a sociologia, ou melhor dizendo, a ciência social, em geral, estaria contribuindo para destacar o homem como um ser autônomo?".

Em outras palavras, a categoria 'homem' ou o ser humano sempre foi central na obra de Guerreiro Ramos e, de acordo com França (1983, p. 125), "não era possível, para Guerreiro, um modelo de homem ou uma verdade preestabelecida, mas esse era um processo de busca, de caminhada permanente". Assim, 0 homem para Guerreiro Ramos, é um ser em constante busca de desenvolver e de atualizar suas potencialidades. Mas, sobretudo, um ser a quem a racionalidade é inerente e só a ele podemos chamar de racional. "Na obra do Guerreiro, não se admite a possibilidade de a razão ser um atributo além do ser, isto é, um atributo que não somente um atributo do indivíduo, do ser humano" (REZENDE, 1983, p. 126).

Nessa perspectiva, como destacam Azevedo e Albernaz (2006, p. 13), são duas as características fundamentais do homem parentético: "a primeira, o fato do homem parentético ser definido como um ser racional; a segunda, o empenho deste em atualizar suas potencialidades". Ainda, segundo Guerreiro Ramos (1981, p. 28), "pelo exercício da razão, e vivendo de acordo com os imperativos éticos dessa razão, o homem transcende a condição de um ser puramente natural e socialmente determinado, e se transforma num ator político". Desse modo, de acordo com Azevedo e Albernaz (2006, p. 134), "a presença de tipos parentéticos nas sociedades assinalaria um acréscimo de qualidade de vida (política) e liberdade humana significativo".

De modo específico, são estas as duas características que merecem destaque e distinguem o homem parentético de Guerreiro Ramos dos demais: um ser de razão e com um incessante empenho na atualização de suas potencialidades humanas. "Dessa forma, as noções de realização pessoal (personal actualization), 
autorrealização (self actualization) e crescimento pessoal (personal growth) são essenciais para a compreensão de homem em Guerreiro Ramos" (AZEVEDO e ALBERNAZ, 2006, p. 14).

Importante lembrar, ainda, que Guerreiro Ramos (1984) assinalava a necessidade do reconhecimento e estímulo à existência do homem parentético; aquele homem que não iria esforçar-se demasiadamente apenas para obter sucesso, segundo os padrões convencionais, como faz aquele cujo objetivo é só alcançar altos cargos na organização. O homem parentético, de acordo com Guerreiro Ramos (1984, p. 9), "poderia ser um grande empreendedor [...]. Não trabalharia apenas para fugir à apatia ou indiferença, porque 0 comportamento passivo iria ferir seu senso de autoestima e autonomia. Iria esforçar-se para influenciar o ambiente, para retirar dele tanta satisfação quanto pudesse". Para o homem parentético, as organizações, como são limitadas pela racionalidade funcional, têm de ser tratadas segundo seus próprios termos relativos, mas, nestas mesmas organizações, também, é possível obter satisfação e autonomia, empreender, criar e se emancipar.

Nas palavras de Guerreiro Ramos (1984, p. 8), homem parentético porque consegue colocar entre 'parênteses', em 'suspenso' "a crença no mundo comum, permitindo ao indivíduo alcançar um nível de pensamento conceitual e, portanto, de liberdade". Em outros termos, o homem parentético é aquele que não é aprisionado pelo imediatismo ou apenas pelas circunstâncias imediatas que, também, precisam da sua atenção. Ao contrário, o homem parentético responde às questões imediatas e, ainda, tem a capacidade de examinar a organização de forma crítica, ou seja, coloca a organização entre parênteses e a avalia como um espectador. Ele busca, deliberadamente, o olhar diferenciado, a perspectiva de um estranho em seu próprio meio social, de maneira a maximizar sua compreensão da organização e da vida para poder agir e interferir para transformar o que está posto, o que está convencionalmente estabelecido.

$\mathrm{Na}$ realidade, o homem parentético não pode deixar de ser um participante da organização. Porém, justamente por tentar ser autônomo, ele não pode ser psicologicamente enquadrado como aqueles indivíduos que se comportam de acordo com os modelos reativo e operacional. Ele possui uma consciência crítica altamente desenvolvida das premissas de valor presentes no dia-a-dia. (GUERREIRO RAMOS, 1984, p. 7).

Mas não é possível aceitar e tampouco é crível que as características do homem parentético só possam ser encontradas em homens excepcionais. "De fato, no passado, tais padrões puderam ser detectados apenas em indivíduos excepcionais. Sócrates, Bacon e Maquiavel, por exemplo", pois possuíam a capacidade que Ihes possibilitou perceber suas respectivas sociedades como arranjos precários. "Enquanto a massa da população nessas sociedades interpretava a si própria e à realidade social de acordo com as definições convencionalmente estabelecidas", eles tiveram a capacidade, examiná-las com visão crítica, além do que estava posto (GUERREIRO RAMOS, 1984, p. 8).

Segundo o próprio Guerreiro Ramos (1984, p. 8), o homem parentético, também, é "simultaneamente, um reflexo das novas circunstâncias sociais, que agora são mais perceptíveis nas sociedades industriais avançadas, como a dos EUA, que irão prevalecer eventualmente pelo mundo inteiro, e uma reação a elas".

Assim, do mesmo modo que os indivíduos foram educados para o desenvolvimento do homem operacional, que se preocupa, fundamentalmente, com a manutenção do sistema social e, do homem reativo, cujo objetivo é, basicamente, o ajustamento ao contexto do trabalho e não seu crescimento pessoal (GUERREIRO RAMOS, 1984, p. 5), faz-se necessário educar para que os indivíduos desenvolvam as características do homem parentético, ou seja, para que desenvolvam a capacidade de colocar as circunstâncias ou sua realidade entre parênteses, analisa-las e, a partir, daí propor mudanças e transformar a realidade, ainda que comece por transformar, apenas, a sua própria realidade, seu contexto social.

Destaca-se que este indivíduo se assemelha ao sujeito cujas características buscam ser desenvolvidas nos programas de educação empreendedora. Isto posto que, o empreendedor, assim como o homem parentético, não limita às condições postas, à realidade estabelecida, portanto, às condições convencionalmente estabelecidas da sociedade a que pertence. Ao contrário, o empreendedor, como homem parentético, busca autorrealização, autonomia e emancipação. Deste modo, a formação para 0 
empreendedorismo ou para a atitude empreendedora desde a educação básica seria fundamental, tanto para o desenvolvimento das organizações, quanto para dos indivíduos que as compõem. Em outras palavras, a educação empreendedora (ensino do empreendedorismo) contribuiria para a formação e desenvolvimento do homem parentético.

Isto posto que, o efeito da educação empreendedora tende a ter mais resultados o quanto antes for iniciada. Isso é o que mostra, por exemplo, o estudo de Huber, Sloof e Van Pragg (2012), ao analisar um programa de ensino aplicado em 63 escolas primárias, compostas por 118 classes e 2.751 alunos, durante os anos de 2010 e 2011, na Suécia. O resultado dessa pesquisa apresenta uma significativa contribuição dessa prática para o desenvolvimento de habilidades como as de autoconhecimento, previsão de riscos, criatividade, autocrítica e proatividade.

Destaca-se, ainda, que o ensino do empreendedorismo é reconhecido com um dos pilares da educação definidos pela Organização das Nações Unidas para a Educação, a Ciência e a Cultura (UNESCO). Além de "Aprender a Conhecer", "Aprender a Fazer", "Aprender a viver com os outros" e "Aprender a ser", no Projeto Regional de Educação para a América Latina e o Caribe, em 1998, foi estabelecido o pilar, "aprender a empreender". Acrescido aos quatro já estabelecidos, em 1996, pelo Relatório Delors da Comissão para a Educação no século XXI da UNESCO (UNESCO, 1999).

\section{Procedimentos metodológicos}

Com o objetivo de identificar como está configurada a pesquisa sobre educação empreendedora (ensino do empreendedorismo) na educação básica no Brasil, especialmente no campo de estudos da Administração, foi utilizada a análise bibliométrica. Este método envolve um conjunto de procedimentos, leis e princípios que, aplicados a métodos matemáticos e estatísticos, permite ao pesquisador mapear determinada produção científica, utilizando-se de documentos com propriedades similares (ARAÚJO, 2006; MACIASCHAPULA, 1998) que neste caso, é definido pela temática da educação empreendedora (ensino do empreendedorismo) na educação básica no Brasil. Como este tipo de abordagem não é uma novidade no campo de estudos da Administração; ao contrário, vem sendo cada vez mais explorada e utilizada pelos pesquisadores, optou-se por não a descrever pormenorizadamente. Interessa saber, no entanto, que para a análise bibliométrica, foi realizado um levantamento dos artigos da área de Administração disponíveis nas bases Scientific Electronic Library Online (SciELO) e Scientific Periodicals Electronic Library (SPELL).

Segundo Bardin (2006, p. 38), a análise de conteúdo consiste em "um conjunto de técnicas de análise das comunicações, que utiliza procedimentos sistemáticos e objetivos de descrição do conteúdo das mensagens". Sua principal finalidade é o enriquecimento da leitura dos textos selecionados. Os artigos podem ser manuseados na busca por respostas às questões de pesquisa, tornando possível identificar 0 que os pesquisadores de determinada área estão afirmando a respeito do tema em estudo (VERGARA, 2005). Certamente, há a necessidade de interpretar, ao longo do tempo, o que está sendo estudado e comunicado pelos pesquisadores da área, neste caso a Administração.

Para a interpretação dos textos, o processo de análise de conteúdo envolveu várias etapas que permitem dar significado aos dados coletados (MINAYO, 2001; CRESWELL, 2007; FLICK, 2009). Nesta pesquisa, a metodologia utilizada para a interpretação dos textos foi a desenvolvida por Bardin (2006) que se estrutura em três fases: pré-análise; exploração do material; e tratamento dos resultados, dos quais também fazem parte a inferência e a interpretação. Na pré-análise, o material é organizado com o objetivo de torná-lo operacional, sistematizando as ideias iniciais. Nesta etapa, realiza-se uma leitura superficial dos textos coletados para conhecê-los. Após esta leitura de contato deve-se selecionar, dentre os textos lidos, aqueles que se inserem na temática a ser analisada. A seguir, já com a definição dos artigos, o pesquisador deve definir as categorias de análise e elaborar indicadores que possam ser identificados nos documentos analisados (BARDIN, 2006).

$\mathrm{Na}$ operacionalização deste processo, foram consultadas as bases Scientific Electronic Library Online 
(SciELO) e Scientific Periodicals Electronic Library (SPELL). Inicialmente, realizou-se uma busca ampla nas bases científicas com as seguintes palavras-chave: "educação empreendedora" OU "empreendedorismo nas escolas" OU "ensino do empreendedorismo" OU "pedagogia empreendedora" OU "formação empreendedora" OU "formação de Jovens Empreendedores" OU "formação de empreendedores" OU "ensino de empreendedorismo" OU "ensinando empreendedorismo" OU "desenvolvimento de competências empreendedoras" OU "educação do empreendedorismo". Adicionalmente, visando garantir um mapeamento censitário do campo, foram realizadas outras cinco buscas com as tags: "empreendedorismo" E "educação"; "empreendedorismo" E "ensino"; "empreendedorismo" E "pedagogia"; "empreendedorismo" E "escola"; "empreendedorismo" E "aprendizagem". Na sequência foi realizado o download, organização e exclusão dos trabalhos repetidos.

Foram encontrados 107 artigos selecionados pelos termos anteriormente citados. Em seguida, deu-se início à segunda fase, a de exploração do material, que consistiu na leitura dedicada e atenta dos textos, analisados à luz da temática previamente definida. Foram evidenciadas a quantidade de textos publicados em cada ano, por periódico, o tipo de pesquisa e o tema central abordado. Com a leitura dos artigos, também, foi possível identificar a origem dos pesquisadores e as Instituições de Ensino Superior (IES) às quais estão vinculados os pesquisadores. Durante um período de pouco mais de dois (2) meses, foi realizada uma leitura sistemática e atenta de cada um dos artigos e registrados os seus dados principais como: título, tema central, ano, periódico onde foi publicado, nome dos autores, tipo de pesquisa e estratégias utilizadas, tipo de coleta de dados e o tipo de organização onde foi realizada a pesquisa quando era o caso. Ao final da segunda fase, foram identificados apenas sete (7) artigos cuja temática, de algum modo, abordava a educação empreendedora (ensino do empreendedorismo) em escolas de educação básica.

Na terceira fase, o momento da análise reflexiva e crítica, ponto de culminância da análise de conteúdo, foram destacadas as informações fundamentais para análise, culminando nas interpretações inferenciais, destacando, ainda, segmentos dos textos analisados que podem ser representativos dos conteúdos contemplados (BARDIN, 2006). Destacamos, ainda, que, por uma limitação de espaço, apenas os resultados mais relevantes são apresentados no artigo e nem todos são apresentados graficamente, embora sejam trazidas para o texto algumas "falas" dos artigos analisados como reforço aos achados da pesquisa

\section{Apresentação e análise dos dados: perspectivas a partir das publicações nos periódicos de Administração}

Na primeira fase, consultadas as bases Scientific Electronic Library Online (SciELO) e Scientific Periodicals Electronic Library (SPELL), utilizando as palavras-chave, anteriormente destacadas, foram encontrados 107 artigos. A Tabela 1 mostra o tema de cada um destes artigos localizados na primeira fase da pesquisa.

Tabela 1 - Temas dos Artigos Encontrados na Primeira Fase da Pesquisa no SciELO e SPELL

\begin{tabular}{|l|l|l|l|}
\hline Qtd. & Tema & Qtd. & Tema \\
\hline 7 & Empreendedorismo na educação Básica & 2 & Criação de novos negócios \\
\hline 3 & Empreendedorismo na educação Técnica & 49 & $\begin{array}{l}\text { Empreendedorismo no Ensino Superior } \\
\text { (Graduação e Pós-Graduação) }\end{array}$ \\
\hline 1 & Educação de Jovens e Adultos & 1 & Empreendedorismo coletivo \\
\hline 3 & Empreendedorismo no meio Rural & 4 & Incubadoras de empreendimentos \\
\hline 5 & Perfil Empreendedor & 1 & Empreendedorismo e Sustentabilidade \\
\hline 19 & Casos de Ensino & 3 & Intensão empreendedora \\
\hline 2 & Empreendedorismo Social & 7 & Outros \\
\hline
\end{tabular}

Fonte: Dados da pesquisa.

ISSN 2318-9231

CGE * v $.5 *$ n. 2 * Mai-Ago 2017 * 55-66 
A Tabela 2 indica os periódicos e 0 ano de publicação dos sete (7) artigos selecionados que atendiam à pesquisa em pauta. Observa-se que somente no ano 2004 foi publicado, pela primeira vez, no Brasil um artigo científico sobre o tema. É notório que há pouco interesse por parte dos pesquisadores da área de Administração, embora, o Ministério da Educação venha indicando às universidades, especialmente, aos Programas de Pós-Graduação, a necessidade de sua participação no âmbito do desenvolvimento da educação básica, de forma mais efetiva, a partir de 08 de junho de 2006, com a criação do Observatório da Educação.

De acordo com o Instituto Nacional de Estudos e Pesquisas Educacionais Anísio Teixeira (INEP, 2011, p. 1), o Observatório da Educação é um Programa de fomento que visa ao desenvolvimento de estudos e pesquisas na área de educação tem entre seus principais objetivos estimular o crescimento da produção acadêmica.

Outra iniciativa do Ministério da Educação (MEC) e da Coordenação de Aperfeiçoamento de Pessoal de Nível Superior (CAPES), que mostra essa necessidade de maior envolvimento dos Programas de PósGraduação com a educação básica pode ser observada nos documentos, até então, trienais, produzidos por cada área. No "documento de área 2013", quando da última avaliação, a CAPES, em suas considerações gerais sobre o estágio atual da área de Administração, Ciências Contábeis e Turismo, reconhece que "a área não tem, historicamente, atuado na perspectiva de contribuir com a educação básica como foco prioritário". Apesar disso, "reconhece a relevância de garantir a qualidade na educação básica como elemento para o avanço da competitividade do país" e "entende que pode contribuir para reduzir o problema de diferentes formas" (CAPES, 2013, p.3).

Apesar de todos os incentivos e indicativos da realização de pesquisas que envolvam a educação básica aos pesquisadores da área de Administração, ainda, verifica-se o pouco interesse em temas vinculados à educação básica e, especialmente, no que tange à educação empreendedora ou ensino do empreendedorismo neste âmbito. Isto posto que, apesar da criação do Observatório da Educação, em 2006, que trouxe incentivos, inclusive financeiros para a pesquisa na área, desde lá, apenas seis (6) artigos foram produzidos ao longo de quase 10 anos. Como mostra a Tabela 2, em 2013, houve um pequeno aumento no número de publicações, não se encontrando nada mais nos anos posteriores.

Tabela 2 - Periódicos nos quais foram localizados os artigos com a temática em pauta por ano

\begin{tabular}{|l|l|l|l|l|l|}
\hline Revista & 2004 & 2009 & 2011 & 2012 & 2013 \\
\hline Revista de Negócios & 1 & & & & \\
\hline Revista de Ciências da Administração & & & & & 1 \\
\hline Pensamento Contemporâneo em administração & & 1 & & & \\
\hline EBAPE & & & 1 & & \\
\hline Educação e Pesquisa & & & & 1 & \\
\hline APGS & & & & & 1 \\
\hline $\begin{array}{l}\text { Revista de Empreendedorismo e Gestão de Pequenas } \\
\text { Empresas }\end{array}$ & & & & & 1 \\
\hline
\end{tabular}

Fonte: Dados da pesquisa.

O primeiro artigo publicado no Brasil sobre o tema, em 2004, foi o trabalho de Fernando Dolabela, "Pedagogia Empreendedora", na "Revista de Negócios". Neste artigo, organizado como um roteiro de entrevista, Dolabela apresenta uma metodologia de ensino do empreendedorismo para a educação básica criada pelo próprio autor, em parceria com a ONG Visão Mundial. 
A Pedagogia Empreendedora e o empreendedorismo que eu defendo, que eu pratico, é aquele que pode provocar a mudança cultural. Estamos falando de mudança, e não de transferência de um conteúdo cognitivo convencional. Estamos falando de uma nova forma de relacionamento entre as pessoas porque é esse relacionamento que estimula ou inibe a capacidade empreendedora. Um relacionamento fortemente hierarquizado, autocrático, tende a destruir a capacidade empreendedora. Já um relacionamento democrático, em rede, onde todos têm a mesma autonomia, têm o poder de influenciar seu próprio futuro e 0 de sua comunidade; tende a disseminar o empreendedorismo. (DOLABELA, 2004, p. 128)

O trabalho de Dolabela (2004) preconiza o debate do ensino do empreendedorismo na educação básica no Brasil, sendo citado por todos os artigos que o sucederam e que fazem parte desta análise. De acordo com 0 autor, no processo de ensino de empreendedorismo

ele (estudante) se sente protagonista e integrante do processo educacional. A educação empreendedora leva o aluno a criar caminhos, estratégias, e a escolher processos para transformar seu sonho em realidade. Dispara um processo de criação, de criatividade, pondo em uso todo o patrimônio existencial do aluno, que é diverso, que é único. Assim, ele se sente capaz e comprometido com a criação de seus próprios caminhos (DOLABELA, 2004, p. 129)

O estudo de Dolabela marca o início não só do debate científico como também o prático. No mesmo ano da publicação deste artigo, 2004, iniciavam os dois principais programas de ensino do empreendedorismo nas escolas de educação básica, que, ainda, continuam a ser implementados no Brasil. Ademais, no Rio de Janeiro, o Sistema Brasileiro de Apoio às Micro e Pequenas Empresas (Sebrae) criou, em 2004, o Programa de Formação de Empreendedores - "Primeiros Passos", que se originou na escola Gay Lussac, em Niterói, e, posteriormente, se expandiu para todo o estado. Já em São Paulo, o Programa de Formação de Jovens Empreendedores, também do Sebrae, começou a ser desenvolvido em escolas de educação básica, visando promover a cultura empreendedora.

Em 2009, foi publicado o segundo artigo, "As vantagens de aprendizado do empreendedorismo: um estudo desde 0 ensino de base até o superior", na Revista Pensamento Contemporâneo em Administração, de Robson Moreira Cunha, Elisa Lemos Soares e Carlos Fontanilhas. Os autores desenvolvem 0 texto apresentando o contexto histórico do empreendedorismo no Brasil, analisando as principais dificuldades de implementar o empreendedorismo na educação formal brasileira. Ao mesmo tempo, apontam as vantagens de se estimular o empreendedorismo como parte de uma iniciativa para torna-lo para da cultura brasileira e, assim, fomentar o desenvolvimento do país através da criação de novas empresas e, portanto, de emprego e renda.

O Brasil em comparação a países do $1^{\circ}$ Mundo, que há duas décadas investem no ensino de empreendedorismo e na criação de empresas não só no âmbito universitário, mas também no ensino de $1^{\circ}$ e $2^{\circ}$ grau, está engatinhando. Iniciamos, primeiros passos para melhorar este perfil. 0 cenário mudou, mas os profissionais em geral e as escolas de ensino superior ainda não estão totalmente preparadas para esse novo contexto (CUNHA, SOARES e FONTANILHAS, 2006, p. 72).

Os autores, ainda, assinalam que, na época, o estágio da educação empreendedora no país, as grandes falhas eram a falta de investimentos, a falta de discussão sobre empreendedorismo em sala de aula e a falta de preparar dos professores para a educação empreendedora e, mesmo para ensinar empreendedorismo.

O terceiro artigo, publicado no Cadernos EBAPE.BR, "Competências empreendedoras e processos de aprendizagem empreendedora: modelo conceitual de pesquisa", de Marcia Aparecida Zampier e Adriana Roseli Wünsch Takahash, em 2011, não trata, especificamente, mas tangencia o tema. É um artigo cunho teórico que busca promover uma análise sobre o competências empreendedoras e aprendizagem do empreendedorismo. As autoras apresentam que a redução dos postos de trabalho e a dificuldade do auto sustento, podem ser solucionadas, conforme

A compreensão dos processos de aprendizagem do empreendedor e de como ele desenvolve suas competências podem subsidiar a formulação de políticas públicas e de tecnologias sociais para minimizar 0 impacto desses problemas, tanto em benefício do indivíduo empreendedor quanto do desenvolvimento ISSN 2318-9231

CGE * v . 5 * n. 2 * Mai-Ago 2017 * 55-66 
econômico do país, como, por exemplo, oferta de microcrédito e de variados tipos de capacitação e treinamento voltados ao empreendedorismo. (ZAMPIER e TAKAHASHI, 2011, p. 581)

De acordo com Zampier e Takahash (2011), ainda não necessárias pesquisas que interrelacionem aprendizagem empreendedora e competências empreendedoras para que se obtenha maior potencial explicativo de uma dada realidade socioeconômica, o que em muito poderia contribuir para o avanço do ensino do empreendedorismo na educação formal, principalmente, através de políticas públicas.

O quarto artigo, de 2012, de Alessandro de Melo, publicado na Revista Educação e Pesquisa, oriundo de sua Tese de Doutorado, apresenta uma perspectiva crítica do ensino do empreendedorismo na escola. 0 artigo analisa a educação básica proposta da Confederação Nacional da Indústria nos anos 2000 e sua relação com o empreendedorismo. Para o autor, o ensino do empreendedorismo é fruto do conflito entre trabalho e capital, cujo propósito é responsabilizar o trabalhador por sua própria carreira. Nesse sentido, essas políticas educacionais governamentais oriundas da burguesia industrial brasileira teriam, segundo 0 autor, como objetivo a manutenção da ordem social para o fim das lutas entre capital e trabalho (MELO, 2012).

O que é preciso compreender para a leitura dos documentos mais recentes da CNI é o cenário capitalista vigente desde os fins do século XX e na atualidade. Tal cenário é caracterizado pela ampla e radical competitividade da indústria brasileira com as indústrias do mundo inteiro. Quanto mais extensa e radical é essa competição, mais necessário se faz tornar melhores os fatores que ampliam a competição da indústria nacional; dentre esses fatores, a educação não é de menor importância, e sempre está presente nos documentos da entidade. A questão levantada de um ponto de vista crítico é a redução da educação à formação de capital humano, o que é um projeto unidimensional de formação para o trabalho abstrato, e não um projeto emancipatório de educação (MELO, 2012, p. 31)

De acordo com este autor, desde a educação infantil e fundamental, a meta seria a formação cidadã dos filhos dos trabalhadores da indústria, não só das escolas do Serviço Social da Indústria, mas das escolas em geral. Melo (2012, p. 35) assinala que "a educação, portanto, tem como finalidade contribuir para 0 desenvolvimento sustentável do país, meta desse programa da Confederação Nacional da Indústria". Assim, "mais uma vez os industriais explicitam a relação de subordinação da escola às demandas produtivas, o que é apresentado discursivamente como uma necessidade premente da sociedade".

O quinto artigo, já publicado em 2013, de Cândido Borges, Estela Najberg, Vicente Rocha Soares Ferreira e Clara Santos Costa, no periódico Administração Pública e Gestão Social, trabalham no artigo no sentido de apresentar e analisar as recomendações dos pesquisadores brasileiros que possam alimentar as políticas de empreendedorismo no Brasil. De acordo com Borges et al (2013, p. 3), "é importante que a produção acadêmica dê origem a conhecimentos que ajudem governos e organizações do sistema de apoio, como 0 Serviço Brasileiro de Apoio às Micro e Pequenas Empresas, na formulação e execução de políticas, que possam fomentar e favorecer a ação de empreendedores.

Governos precisam de subsídios para elaborar suas ações relacionadas com o empreendedorismo. Os pesquisadores brasileiros deveriam ter um papel preponderante na geração desses subsídios; mas, considerando a produção apresentada no EGEPE, não é o que está acontecendo. Algumas condições estruturais da pesquisa em empreendedorismo no Brasil podem explicar essa situação. Primeiro, o campo é recente no Brasil e ainda são poucos os pesquisadores e os programas de Pós-Graduação com linhas de pesquisa que tenham como foco o empreendedorismo. Segundo, ainda não há nenhum grupo de pesquisa cadastrado no CNPq que trabalhe especificamente sobre políticas públicas de empreendedorismo (BORGES et al, 2013, p. 16).

Conforme se observa, pela 'fala' dos autores, embora os pesquisadores da própria área de empreendedorismo tenham um papel fundamental na recomendação de políticas públicas para 0 empreendedorismo que poderiam, inclusive, promover a educação empreendedora na educação básica, 
não é o que se tem registrado ao longo dos anos.

O sexto artigo, também de 2013, Cristiana Fernandes de Muylder, Alexandre Teixeira Dias e Cláudio Luiz Oliveira, publicado na Revista de Ciências da Administração, Is it possible to teach entrepreneurship? comparative analysis with brazilian students, busca verificar se é possível ensinar o empreendedorismo nas escolas. Para isso, foi realizada uma survey com 175 alunos das séries iniciais e 138 das finais de uma escola de ensino médio que possui um programa de ensino do empreendedorismo. Constatou-se, segundo os alunos entrevistados, que a educação por eles recebida contribuiu significativamente para 0 desenvolvimento de habilidades como lidar com o risco, capacidade de inovar e maturidade profissional.

O sétimo e último artigo analisado, também de Fernando Dolabela, mas, agora, em parceria com Louis Jacques Filion, foi publicado na Revista de Empreendedorismo e Gestão de Pequenas Empresas, em 2013. Os autores apresentam os avanços da aplicação da pedagogia empreendedora no país nos últimos 10 anos.

O programa abriu portas para o desenvolvimento de novas abordagens educacionais e materiais que permitirão aos alunos refletirem sobre si mesmos, sobre o seu futuro, além de desenvolverem a sua imaginação, Ihes dando ferramentas para melhor satisfazer o seu desejo de conquista. $O$ experimento descrito aqui provavelmente é único no mundo, e pode servir de modelo para transformar outros sistemas educacionais, tanto nos países emergentes e naqueles que desejam revitalizar o desenvolvimento de sua maior riqueza natural - o potencial empreendedor dos seus recursos humanos. (DOLABERA e FILION, 2013, p. 175)

De acordo com Dolabela e Filion (2013, p. 135), "a metodologia pedagógica conhecida como Pedagogia Empreendedora foi proposta e implementada em escolas de ensino fundamental, visando facilitar a aprendizagem empreendedora pelas crianças e adolescentes".

Ao utilizar os sistemas de ensino público e privado em sua estratégia de implementação, a Pedagogia Empreendedora valoriza a escola como representante da comunidade. As escolas são entendidas como sendo o local para se adquirir a capacidade de construir e lidar com o futuro. Neste sentido, a escola representa o microcosmo da sociedade que pode ajudar a criar o futuro desejado. Uma das características da Pedagogia Empreendedora é que a comunidade deve participar ativamente como aprendiz e como apoiadora, sendo fonte da educação e participando da definição dos objetivos educacionais. (DOLABERA e FILION, 2013, p. 153).

Por fim, de acordo com Dolabela e Filion (2013, p. 156), "a metodologia da pedagogia empreendedora foi formulada para o ensino fundamental com o intuito de oferecer às crianças e jovens um terreno mais fértil para a expressão da sua criatividade e empreendedorismo". Por isso, mesmo, segundo Dolabela e Filion (2013, p. 173, a ideia em cada escola, por exemplo, é identificar recursos humanos que ajudem "a construir pontes que permitam à educação empreendedora se estabelecer e começar a se desenvolver. Esta perspectiva implica que as pessoas percebam um interesse comum na cooperação, o que pode ajudá-las a pôr de lado as diferenças individuais".

Destaca-se, ainda, que os pesquisadores que já publicaram artigos que, de algum modo, abordaram a questão da educação empreendedora ou do ensino do empreendedorismo na educação básica no Brasil, são oriundos de apenas sete (7) Instituições de Ensino Superior: Universidade Federal de Goiás, Universidade Federal do Paraná, Fundação Dom Cabral, Universidade FUMEC, Universidade Estadual do Centro Oeste, Universidade Federal Fluminense e HEC Montréal.

O que se observa, portanto, é o registro de poucas pesquisas sobre o tema da educação empreendedora ou do ensino do empreendedorismo na educação básica no Brasil que, pode estar relacionada à falta de disseminação de programas específicos na área.

Quanto aos trabalhos que compõe este estudo, observa-se uma congruência no sentido de que o ensino do empreendedorismo é capaz de oferecer ferramentas aos alunos para que possam buscar sua autonomia, sua emancipação. Certamente, com exceção do artigo de Melo (2012) que faz uma crítica ao ensino do empreendedorismo, posto que 0 autor acredita que seria mais uma manobra do capital para subordinar os 
trabalhadores.

De acordo com os autores que propõem metodologias para o ensino do empreendedorismo ou, mesmo que, apenas buscam estudar os resultados do ensino do empreendedorismo, verifica-se que há concordância que a educação empreendedora pode propiciar ao educando uma visão "entre parênteses" ou "em suspenso" de si mesmo e da sociedade. Esta reflexão parentética poderia levar educando "a esforçar-se para influenciar o ambiente, para retirar dele tanta satisfação quanto pudesse" como já assinalou Guerreiro Ramos (1984, p. 9).

Também, é possível observar que há uma similaridade dos preceitos preconizados pela literatura, nos textos analisados neste artigo, que aborda o ensino do empreendedorismo em relação ao novo homem descrito por Guerreiro Ramos. Os educandos que tenham sido inseridos em programas de educação empreendedora, assim como o homem parentético, poderia ser capaz de perceber que é possível trabalhar nas organizações, empresariais ou não, e, nestas mesmas organizações, descobrir que, também, é possivvel obter satisfação e autonomia, empreender, criar e se emancipar. Isto porque, sua visão de mudo transcende os limites organizacionais, não se limitando ao modo racional-funcional de pensar e existir.

\section{Considerações finais: estimulamos o desenvolvimento do homem parentético?}

A partir dos registros encontrados, é possível afirmar que há no Brasil um movimento para desenvolver programas de educação empreendedora ou de ensino de empreendedorismo na educação básica cujas caraterísticas que pretendem ser desenvolvidas nos educandos se assemelham àquelas de formação do homem parentético de Guerreiro Ramos (1984).

Desde 2004 já existe um programa de pedagogia empreendedora para escolas de ensino fundamental e médio com objetivo de formar pessoas que possam definir seus próprios caminhos. De acordo com os textos aqui analisados, a educação formal tradicional no Brasil busca formar empregados para as empresas. A educação empreendedora, por sua vez, busca, no processo de formação, oferecer um caminho de liberdade para a maior quantidade possível de estudantes, para aqueles que querem sonhar e transformar seus sonhos em realidade.

A educação empreendedora não tem intenção de substituir a educação formal tradicional brasileira. Ela busca fazer parte desta formalidade para criar e desenvolver a cultura no empreendedorismo no Brasil. Os programas de educação empreendedora tratados pelos autores aqui analisados, buscam elevar a autoestima e o nível de controle das pessoas sob seu próprio destino, propiciando-lhes maior autonomia e, principalmente, autorrealização e crescimento pessoal, características essenciais "para a compreensão de homem em Guerreiro Ramos", como já destacado por Azevedo e Albernaz (2006, p. 14).

Por fim, é preciso lembrar que o próprio Guerreiro Ramos (1984) afirmava que, se era possível educar os sujeitos para o desenvolvimento do homem operacional, que se preocupa, fundamentalmente, com a manutenção do sistema social e, do homem reativo, cujo objetivo é, basicamente, o ajustamento ao contexto do trabalho e não seu crescimento pessoal; também seria possível educar para desenvolver o homem parentético.

Em outros termos, faz-se necessário educar para que os indivíduos desenvolvam as características do homem parentético, ou seja, para que desenvolvam a capacidade de colocar as circunstâncias ou sua realidade entre parênteses, analisa-las e, a partir, daí propor mudanças e transformar a realidade, ainda que comece por transformar, apenas, a sua própria realidade, seu contexto social. Este também é o resultado proposto pela educação empreendedora desde a educação básica no Brasil.

\section{Referências}

AZEVEDO, Ariston e ALBERNAZ, Renata. A "antropologia" do Guerreiro: a história do conceito de homem parentético - m memória a Eliana Guerreiro Ramos (1949-2003). Cadernos EBAPE.BR, Rio de Janeiro, v. 4, n. 3, p. 01-19, Out. 2006 
BORGES, Cândido et al. Perfil das Recomendações dos Pesquisadores Brasileiros às Políticas Públicas de Empreendedorismo. Administração Pública e Gestão Social, Viçosa, v. 5, n. 1, pp. 01-19, jan./mar. 2013.

CAPES-Coordenação de Aperfeiçoamento de Pessoal de Nível Superior. Documento de área 2013: Administração, Ciências Contábeis e Turismo. 2013. Disponível em $<$ https://www.capes.gov.br/images/stories/download/avaliacaotrienal/Docs_de_area/Administra\%C3\%A7\% C3\%A30_doc_area_e_comiss\%C3\%A30_16out.pdf>

CUNHA, Robson M., SOARES, Elisa., FONTANILHAS, Carlos. As vantagens de aprendizado do empreendedorismo: um estudo desde 0 ensino de base até o superior. Revista Pensamento Contemporâneo em Administração. Rio de Janeiro, v. 3, n. 3, p.62-73, set./dez. 2009.

CRUZ JÚNIOR, João Benjamin Cruz et al. Empreendedorismo e educação empreendedora: confrontação entre a teoria e prática. Ciências da Administração, v. 8, n. 15, p. 1-15, 2006.

DOLABELA, Fernando. Pedagogia empreendedora. Revista de Negócios, v. 9, n. 2, p. 127-130, abr./jun., 2004.

DOLABELA, Fernando e FILION, Louis Jacques. Fazendo revolução no brasil: a introdução da pedagogia empreendedora nos estágios iniciais da educação. Revista de Empreendedorismo e Gestão de Pequenas Empresas, v.3, n.2, p. 134-181, 2013.

FRANÇA, Célio. Quarto painel: a teoria da delimitação dos sistemas sociais. Simpósio Guerreiro Ramos: resgatando uma obra. Revista de Administração Pública, Rio de Janeiro, v.17, n.2, p.93-99 e 126, abr.jun. 1983.

GUERREIRO RAMOS, Alberto. A nova ciência das organizações: uma reconceituação da riqueza das nações. Tradução: Mary Cardoso. Rio de Janeiro: Editora FGV, 1981.

GUERREIRO RAMOS, Alberto. Modelos de homem e a teoria administrativa. Revista de Administração Pública, Rio de Janeiro, v.18, n.2, p. 3-12, abr./jun. 1984.

HUBER, Laura Rosendahl; SLOOF, Randolph; VAN PRAAG, Mirjam. The effect of early entrepreneurship education: Evidence from a field experiment. European Economic Review, v. 72, p. 76-97, 2014.

INEP-Instituto Nacional de Estudos e Pesquisas Educacionais Anísio Teixeira. Observatório da Educação: o que é. Brasília: INEP, 2011.

MELO, Alessandro de. A educação básica na proposta da Confederação Nacional da Indústria nos anos 2000. Educação e Pesquisa, São Paulo, v. 38, n. 1, p. 29-45, 2012.

MUYLDER, Cristiana Fernandes de, DIAS, Alexandre Teixeira e OLIVEIRA, Cláudio Luiz. Is it possible to teach entrepreneurship? comparative analysis with brazilian students. Revista de Ciências da Administração • v. 15, n. 37, p. 82-91, dez. 2013

REZENDE, Ubiratan S. Quarto painel: a teoria da delimitação dos sistemas sociais. Simpósio Guerreiro Ramos: resgatando uma obra. Revista de Administração Pública, Rio de Janeiro, v.17, n.2, p.93-99 e 126, abr./jun. 1983.

SCHREIER, J. W.; KOMIVES, J. L. The entrepreneur and new enterprise formation: a resource guide. Milwaukee: Center for Venture Management, 1973.

UNESCO - Organização das Nações Unidas para a Educação, a Ciência e a Cultura. A UNESCO e a educação na América Latina e Caribe 1987-1997. Santiago do Chile, 1999.

ZAMPIER, Marcia A. e TAKAHASHI, Adriana R. W. Competências empreendedoras e processos de aprendizagem empreendedora: modelo conceitual de pesquisa. Cadernos EBAPE.BR, v. 9, Edição Especial, artigo 6, Rio de Janeiro, p.564-585, Jul. 2011. 